\title{
OS ARTÍFICES DA METRÓPOLE: ANOTAÇÕES SOBRE A TRANSFORMAÇÃO DA VIDA URBANA CARIOCA DEPOIS DA BELLE ÉPOQUE
}

\author{
André Luiz Paulilo
}

\begin{abstract}
RESUMO: O artigo propõe-se a evidenciar o repertório de práticas envolvido na remodelação urbana da cidade do Rio de Janeiro. Depois de apresentar as referências históricas que presidiram a análise, o texto aponta as ilusões, as marcas e as transformaçōes da vida carioca ocorridas com a assunção geral e vertiginosa do urbano. $\mathrm{O}$ texto detém-se na consolidação dos instrumentos de intervenção social nos centros de maior concentração populacional. Ele é desenvolvido segundo três eixos: o urbanismo, a reforma social e a educação pública. O artigo conclui circunscrevendo o alcance do esforço realizado depois da Belle Époque para fazer do Rio de Janeiro uma metrópole cosmopolita.
\end{abstract}

Palavras-chave: Urbanismo. História cultural da educação. Escolarização moderna. Políticas públicas.

\section{THE CRAFTSMEN IN THE METROPOLIS: NOTES ON THE TRANSFORMATIONS OF THE CARIOCA URBAN LIFE AFTER THE EDWARDIAN ERA}

ABSTRACT: This paper aims at highlighting the repertory of practices wrapped up in the urban remodeling of the city of Rio de Janeiro. After presenting the historical references governing its analyses, the text pinpoints the illusions, marks and transformations of the carioca life that followed the generic and vertiginous assumption of urbanity. The text dwells on the consolidation of the instruments of social intervention in the centers of major population concentration. It develops according to three axes: urbanism, the social reforms and public education. The paper concludes delineating the

Doutorando em Educação na Universidade de São Paulo (USP), professor titular em História na rede municipal de ensino de São Paulo e integrante do Núcleo Interdisciplinar de Estudos e Pesquisa em História da Educação (NIEPHE) da USP. E-mail: paulilo@usp.br 
Os artifíces da metrópole: anotações sobre a transformação da vida urbana carioca...

reach of the effort realized after the Edwardian era to make Rio de Janeiro into a cosmopolitan metropolis.

Key words: Urbanism. Cultural history of education. Modern schooling. Public policies.

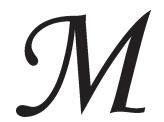

eu objetivo neste texto é a descrição de um certo número de mudanças na vida urbana carioca depois da Belle Époque e a análise do repertório de açōes envolvido na reconfiguração da cidade do Rio de Janeiro. Convém iniciar por aquilo que a historiografia especializada reconhece ser as condições desse repertório, o modo de constituição daquele certo número de mudanças. Inicialmente, a "regeneração da cidade": são incontáveis os vestígios reunidos sobre a condenação dos hábitos e costumes considerados tradicionais, a negação da cultura popular, a expulsão da população pobre do centro da cidade (expulsão que para alguns historiadores foi relativa) e o cosmopolitismo identificado com a vida parisiense. Em seguida, o princípio reitor da remodelação está perpetuamente presente na descrição dos meios pelos quais se realizou: saneamento, planificação e ordem. Ainda nesse contexto, os pesquisadores das reformas urbanas do Rio de Janeiro sabem que prodigiosas novidades elas legaram, e não apenas pela criação de um espaço público central na cidade, pela expansão da sociabilidade de varandas e salóes para as novas avenidas, praças, palácios e jardins e pela incessante busca de uma consciência complementar ao novo espaço físico.

Um último conjunto de registros é encontrado acerca do assunto. De conformidade com o transcurso das reformas, remete a cidade a um fluxo duplo. O correspondente à ordem física que, por sensível, material, está submetida às nuanças da construção e da destruição, da instauração e da renovação, e, sobretudo, aos impulsos da invenção circunstancial de indivíduos e grupos segundo seu momento e situação. Acima dele, o correspondente à ordem dos signos, ligada ao nível simbólico, que consigna à realidade de ruas, edifícios, praças e jardins a mecanicidade dos sonhos da razão. O planejamento, a consolidação da ordem e a capacidade técnica da engenharia são tomados como expressões da cultura das camadas altamente urbanizadas. A transladação da ordem social e cultural a uma realidade física é lembrada como desmembramento da comunidade brasileira em duas sociedades antagônicas que ninguém admitia mais ver juntas, embora 
fossem uma e a mesma, os grupos tradicionais e a burguesia citadina sintetizada pela oposição cidade operosa x campo indolente.

A transformação do espaço público foi enorme. É necessário lembrar que resultou de muitos planos diferentes. Eles podem ser divididos em três grandes rubricas: o bota-abaixo da administração Pereira Passos (1902-1906), a intensa abertura viária promovida por Paulo de Frontin (1906-1907) e o arrasamento do Morro do Castelo por Carlos Sampaio (1920-1922). Do mesmo modo, podem ser agrupadas sob uma curiosa interseção, pois, no conjunto, são obras de engenheiros cuja agudeza das remodelações destruíram os alicerces de tradiçóes de convivência no perímetro urbano da cidade do Rio de Janeiro. E, dessa perspectiva, são para muitos historiadores o efeito desejável da fabricação de um novo modelo cultural, moderno (Sevcenko, 1986; Monarcha, 1989). Para outros, seus episódios assinalam muitos dos mitos fundadores da concepção política de intervenção e gestão administrativa da cidade (Chalhoub, 1996). Outros, ainda, entendem o empenho técnico observado entre 1902 e 1922 para remodelar a cidade como um momento importante da paulatina substituição da vivacidade da oralidade das comunicaçóes rurais ou suburbanas pelas pautas educativas que as cidades impõem, pelos produtos substitutivos que colocam em circulação, pela extensão dos circuitos letrados que propugnam (Gomes, 1999; Nunes, 1994).

Sem muita margem de dúvida, foi num quadro desse tipo que se constituiu um certo isomorfismo entre planejamento urbano e sua realidade física com todo um conjunto de enunciados. A reflexão que se segue está interessada pela assunção geral e vertiginosa do urbano na consolidação dos instrumentos de intervenção social nos meios de maior fluxo ou concentração populacional.

\section{As ilusões da remodelação urbana}

Sob esse aspecto, o que se passa na década de 1920, especialmente depois das comemorações do centenário da Independência, é indicativo do problema que se quer colocar com este texto. O problema é o seguinte: entender o modo como se procurou evitar as irrupções circunstanciais alheias às normas de apropriação do espaço estabelecidas sob o signo da "cidade civilizada" dos tempos de Pereira 
Os artifíces da metrópole: anotações sobre a transformação da vida urbana carioca...

Passos, entorpecendo-as ou destruindo-as. Como se pretendeu assegurar as representaçóes que traduziam a vontade de edificar tanto a ordem social como a sua realidade física enquanto se corrigiam as práticas inexpertas? Isto é, quais estratégias foram pensadas para, nas justas palavras de Angel Rama, "seguir regendo a vida das coisas dentro de rígidos marcos” (1985, p. 29)?

As respostas encontradas pela comissão urbanística do Rio de Janeiro, organizada em 1927 na administração do prefeito Antônio Prado Júnior, em torno do urbanista francês Alfred Agache, é sugestiva dos termos em que foi colocada a questão:

Definida a função urbana do Rio de Janeiro, impõe-se a necessidade de estabelecer um programa que coordene claramente os dados do problema, inspirando-se, na medida do possível, nos fatos passados, nas reivindicações presentes e nas previsões para o futuro. (Agache, 1930, p. 119).

Este trecho do relatório apresentado por Agache faz do planejamento a estratégia fundamental para organizar a complexidade da vida urbana. Assim, para a remodelação da cidade parece indispensável a Alfred Agache um tratamento racional do crescimento urbano. Faz parte desse mesmo enredo o plano diretor.

O caráter normativo do plano é nítido. A forma como este documento redefine a cidade impunha uma urbanidade racionalizante e totalizadora. De certa forma, fica assentada a importância da predominância do estatuto social nas propostas de uma legislação urbana. Em sua análise sustenta que a parte jurídica do plano diretor é o único meio capaz de conciliar e subordinar os interesses particulares ao interesse geral do mesmo modo que evitar criaçôes desordenadas ou inadequadas (Agache, 1930, p. 126).

Em contrapartida, ficam identificados na crítica feita à organização urbana da cidade do Rio de Janeiro os limites das remodelaçôes realizadas. A crise de crescimento descrita numa das conferências sobre o programa de urbanismo para a capital federal pronunciada por Alfred Agache em fins de julho de 1927, como efeito de um desenvolvimento demográfico e econômico demasiadamente rápido, deixaria expostas as dificuldades de circulação, de saneamento, de ventilação e, portanto, de saúde e funcionamento a quem quisesse vê-las (1930, p. 6-8). Foi o que reconheceu Carlos Sampaio em artigo pu- 
blicado na Revista Brasileira de Engenharia dois meses mais tarde: "Ele diagnosticou que tais males afetavam a nossa metrópole, que, comparada ao corpo humano, sofria de defeitos de respiração, de circulação e de digestão" (1927, p. 131).

O fato é que existe indício claro, tanto no relatório de Agache quanto no noticiário da imprensa, de que tanto a infra-estrutura quanto a configuração estética da cidade enfrentavam dificuldades importantes. O melhoramento das condiçôes de salubridade da capital ocupa um lugar único e exemplar: nele vinham enlaçados desde os problemas de distribuição de água potável e de coleta de lixo até as dificuldades de comunicação entre as várias partes da cidade e de circulação, entre elas, de pessoas ou cargas. A intensificação do processo de parcelamento dos terrenos dos subúrbios cariocas e sua conseqüente mercadização imobiliária. Ainda figuram como preocupaçóes a insuficiência da rede de transportes, a precariedade da substituição, na iluminação urbana, da iluminação de gás pelas lâmpadas incandescentes, a insistência das inundações na estação das chuvas e a inexistência de um padrão arquitetônico para as casas do centro.

Nesse momento, ainda que muito relembrados e valorizados, os diversos melhoramentos realizados na cidade pela plêiade de engenheiros que ocuparam a Prefeitura do Rio de Janeiro davam claras mostras de esgotamento. O elenco de dados reunidos pela historiografia especializada mostra com certa clareza que tais melhoramentos foram incompatíveis com a criação de condições de habitação para a afluência populacional requisitada pela acumulação de capitais viabilizada pelo desenvolvimento da cidade (Fridman, 1999). Nisso está incluído tudo o que habitar implicava para a sociedade urbana da época: escolas, assistência médica, transporte, água, luz, esgoto, atividades de lazer e cultura. Os efeitos desse déficit foram sentidos como máculas da imagem civilizada da cidade remodelada e saneada. As críticas reiteradas ao aspecto urbano da capital da república impressas pelos diversos periódicos atribuíamnas à ocupação desordenada, intensa e constante da cidade. Insistiam em criticar as formas precárias das habitaçôes suburbanas, as profissões exercidas na rua, a ineficiência da ação profilática e os aviltamentos da delinqüência. 
Os artifíces da metrópole: anotações sobre a transformação da vida urbana carioca...

\section{As marcas do real no cotidiano da ocupação da cidade}

Os problemas enfrentados pela administração pública duas décadas depois da reforma Pereira Passos diziam respeito, até certo ponto, à ocupação cotidiana da cidade. Por essa época, a cidade do Rio de Janeiro ressentia-se do aumento da população urbana.

A industrialização foi identificada como o principal foco de atração. Um articulista do Jornal do Brasil entendeu-a como a causa primeira do aumento da população urbana. A concentração era a característica evidente da moderna economia capitalista que, adotando e aplicando a divisão do trabalho e a especialização das indústrias, requeria uma quantidade cada vez maior de trabalhadores (Castro, 1926).

A grande indústria mercê da sua desapiedada concorrência sufocou e matou, de uma vez, as pequeninas indústrias que nas folgas das ocupações campestres ou caseiras se desenvolviam dentro das fazendas. Matou o que se chama o trabalho a domicílio. Esta morte fez desaparecer uma fonte de renda. (Castro, 1926, p. 2)

Aspecto ainda mais grave era a falta de instrumentos da prefeitura para regulamentar a expansão industrial. As fábricas instaladas irregularmente e sem preocupação alguma com a localização e o bemestar das populaçóes operárias atraíram os trabalhadores para as suas imediações. Na Sociedade de Medicina e Cirurgia, o Dr. Castro Barreto resumiu com aguda perspicácia o que se passava depois:

Começa então o núcleo de habitações miseráveis que nenhuma classificação podem ter, porque não preenchem nenhum dos requisitos a uma habitação humana, nem mesmo à uma pocilga: não têm iluminação, porque não têm janelas; não defendem da intempérie; não resguardam da umidade do solo; não têm esgoto nem água; não têm onde cozinhar nem onde lavar. São antes o viveiro e o sementeiro de todas as moléstias parasitárias e infectuosas que se revelam obscuramente numa letalidade humilhante da devastação da tuberculose pulmonar. (Barreto, 1924, p. 1)

Tais comunidades eram insistentemente consideradas a causa da manutenção endemo-epidêmica das várias entidades mórbidas que se julgava já deveriam ter desaparecido da nosografia urbana carioca. As instalações dessas comunidades expunham a precariedade 
das populações operárias que procuravam fixar moradia na zona urbana do Distrito Federal. Sem janelas, rede de água e esgoto ou piso, eram moradias feitas com todo tipo de materiais: latas de gasolina, tábuas de caixões de bambu e barro de pedras secas enroscadas com estopas de fiagem de madeira velha das demoliçôes (Barreto, 1924).

Os bairros miseráveis do perímetro urbano do Rio de Janeiro não alarmavam. Ao contrário, indicavam a própria evolução do crescimento da cidade e o alargamento concomitante aos seus progressos. Portanto, não havia por que estranhar as habitações nas favelas ou nos morros. Mesmo porque os poderes públicos dispunham de um antídoto singular para corrigir tal efeito: o carmatelo e o alvião do progresso que, tal como no Morro do Castelo ou do Senado, transformariam a precariedade humana em ordem urbana. Entretanto, a instalação de novas favelas no próprio coração da magnifica urbs saneada fez com que o cenário apologético das políticas urbanas empreendidas pela prefeitura carioca renovasse seu vínculo histórico com o círculo monstruoso do processo de regeneração.

Para alguns, parecia um pouco tarde. A população ocupava o centro urbano de outras formas. Havia quem procurava ali outras formas de sobrevivência. Uma delas foi motivo de uma coluna na Gazeta dos Tribunaes:

Há uma profissão, das modernas, que esta se alastrando, grandemente, e não será de admirar que muito breve, tanto já são que a necessitam, apareça por aí uma sociedade que as congregue, índice seguro do seu valor numérico. Refiro-me ao camelô. O camelô vende tudo, faz reclamo das coisas mais extravagantes e até dos mais inúteis, mas devido a grande habilidade posta em prática vai fazendo seu negócio. (Fonseca, 1927, p. 3)

Profissão que reconhece a cidade, os pontos de passagem, seu local ideal de trabalho, o comércio ambulante, representado pela figura do camelô, foi mais um componente da ocupação do centro urbano da capital federal. $\mathrm{Na}$ realidade, um pouco mais: outra forma da precariedade das condições de vida da população pobre ou migrante. Muitas das relaçôes sociais desenvolvidas nessas condições passam a ser motivo da atenção das autoridades, sanitárias ou policiais. Era visível à crônica da época a formação de um espaço im- 
Os artifíces da metrópole: anotações sobre a transformação da vida urbana carioca...

portante de marginalidade, constituído por atitudes anti-sociais, fruído dia e noite e identificado com um novo modo de vida, urbano e individualista.

Para além da degradação das condições de moradia e de trabalho, o cotidiano urbano conheceu outras formas de depreciação da vida. O abuso dos tóxicos retratava a frenética procura do prazer. E também a frivolidade que representava essa busca: "Abusa-se em todas as famílias do emprego de entorpecentes. Uma dor qualquer justifica uma injeção de morfina, uma aplicação de cocaína. Depois vem o vício e com o vício a infelicidade" (Fonseca, 1927, p. 3).

Episódios diversos, de equilíbrio precário, e cujo desequilíbrio gerou fenômenos de desorganização que atingiam de uma só vez o espaço, a coletividade e a personalidade. Nesse quadro do comportamento humano em meio urbano, a ação de médicos, juristas, engenheiros e educadores reabilitou as representações de progresso, regeneração e educação de modo categórico e contundente. Uma série de pesquisas sobre os fenômenos da marginalidade (Moraes, 1921; Fontenelle, 1927), da segregação racial (Barreto, 1923), da criminalidade (Santos Neto, 1926; Peixoto, 1932), da delinqüência juvenil (Schiavi, 1926; Marques, 1925), do analfabetismo (Orico, 1918; Frota Pessoa, 1924) ou, ainda, da doença mental, bem representados com a fundação da Liga Brasileira de Higiene Mental em 1923, ain$\mathrm{da}$ apontavam para o intervencionismo social como instrumento necessário à transformação regrada e normativa dos costumes.

O que surpreendia, no entanto, era a ineficiência dessa ação denunciada pelo tipo de ocupação a que a cidade era submetida, pela deficiência técnica apresentada na remodelação do centro urbano e, sobretudo, pela nova incursão da febre amarela no Rio de Janeiro. Parecia ser insidioso ao cidadão carioca testemunhar o contraste entre os morros e as colinas invadidos por uma população miserável e os bairros contíguos que aformoseavam a cidade (Barreto, 1924). Outros episódios esmiuçavam este processo de degradação: o reconhecimento de que a remodelação já feita, mesmo satisfazendo todas as regras da arte na ocasião em que foi construída, encontrava-se em condiçôes de não lhe poderem ser aplicadas algumas regras modernas, pois "a necessidade de progresso determinou exigência de solução diferente daquela que tinha sido adotada” (Sampaio, 1927). 
Os contrastes e os erros proporcionados pela ação sobre a organização urbana da capital eram motivos suficientes para desapontar seus artífices, que esperavam soluçôes definitivas para os problemas urbanos. Mas foi o retorno da epidemia de febre amarela que sublinhou a defasagem existente entre as exigências da sociedade carioca e a realidade da ação das autoridades públicas. O editorial da Revista Brasileira de Engenharia publicada no momento da epidemia, agosto de 1929, percebeu-a como parte significativa do desafio enfrentado pelos quadros técnicos dos poderes públicos. Ressaltava o problema nos seguintes termos:

A rapidez é a característica principal da época presente. Nos dias vividos pela geração atual, mais do que nunca, estacionar é regredir. E se fossem necessárias provas palpáveis, provas vultosas, provas inegáveis de tal assento, bastaria citarmos a recente incursão da febre amarela entre nós, fruto somente da incapacidade de um organismo de defesa que se manteve estacionário, enquanto a cidade crescia, a população se multiplicava e a complexidade da vida urbana se elevava a potências superiores. Foi preciso recuperar o atraso, despendendo, num ano, para paralisar o mal, uma soma de energia que melhor fora aplicada antecipadamente, na ampliação constante da ação profilática, para que ela não regredisse, como regrediu, pelo simples fato de se ter mantido estacionária. (1929, p. 57)

A publicação convida a procedimentos técnicos mais bem controlados. Esse convite, que foi também uma reivindicação, aparece como o arremate visível de uma transformação das condições de manutenção da ordem urbana. À rigidez e permanência de uma organização planejada do espaço sucedeu a codificação permanente da mudança. Esta superava as virtudes da primeira, porque possibilitava lidar com a falta de tempo disponível para prever o modo de neutralização de toda futura desordem. E porque, além disso, proporcionava um modelo cultural operativo adequado aos vaivéns das circunstâncias pelas quais a cidade absorvia seus cidadãos. Esta substituição recobre mais do que designa o movimento que reivindicava para si a experiência do progresso.

De modo inverso, é possível distinguir, além da reivindicação da experiência do progresso, a interdição do "retrocesso". As obras realizadas no Rio de Janeiro durante a presença de Alfred Agache na Comissão Urbanística da cidade fizeram ver esse oco no qual to- 
Os artifíces da metrópole: anotações sobre a transformação da vida urbana carioca...

mavam sentido a incursão da febre amarela, a instalação de novas favelas no coração da cidade saneada, o consumo de narcóticos, a especulação imobiliária e todas as demais formas de afrontamento da liberdade contra o mundo. Na prática, com Agache, a cidade do Rio de Janeiro foi submetida a uma análise na qual o indivíduo e a coletividade implicam-se, desenvolvem-se um a partir do outro e não representam outra coisa senão sua relação mútua. Ainda uma vez no editorial da Revista Brasileira de Engenharia é notável esse novo tipo de registro:

Era inegável a necessidade de um plano de conjunto, bem estudado, e definitivamente aceito como diretriz do engrandecimento da nossa capital. Já se foram os tempos em que os problemas urbanos eram tão simples que a realização dos interesses particulares simplesmente justapostos satisfaziam como solução aos interesses da coletividade. Hoje, se é verdade que, como sempre, são os interesses particulares que criam os problemas de ordem coletiva, já não basta satisfazê-los isoladamente para bem administrar. É necessário analisá-los detidamente, diferenciá-los, classificá-los e integrá-los por fim. Somente a síntese final, coroamento de um trabalho exaustivo de seleção e classificação, poderá ser útil à coletividade. (1929, p. 57)

\section{O urbanismo como reforma social}

Junto à cidade é o próprio discurso do poder que se urbaniza. O plano para gerir as diversas circunstâncias nascidas da aglomeração urbana, reconhecido na série de obras executadas por diversos pontos do Rio de Janeiro em 1928-1929, instaurava o discurso urbanístico. A cidade, então, assistiu, mais que a uma modificação da sua forma, à sua mistificação nos discursos políticos.

A intensificação das operaçôes programadas e controladas fez da organização funcional da cidade um programa político que se atribuiu a função de recalcar as ocasióes de desordem, isto é, segundo Michel de Certeau, "tudo aquilo que não é tratável e constitui portanto os detritos de uma administração funcionalista" (1994, p. 173). Neste discurso, o arruamento da esplanada do Morro do Castelo, a reconstrução do edifício do Teatro João Caetano, a abertura, o calçamento ou o prolongamento de diversas ruas e a remodelação de praças e jardins iam criando seus leitores: "Esperar, portanto, 
pela publicação do projeto final para analisá-lo será deixar escapar uma série de aspectos da questão, então já definitiva e irremediavelmente assentados" (Revista Brasileira de Engenharia, 1929, p. 59).

Enfim, foi no decorrer das obras de aformoseamento, antes mesmo da publicação do "Plano de Remodelação", que as evidências materiais tornaram visíveis o processo de apropriação do sistema topográfico da cidade organizado pela administração pública. A cidade instaurada pelo discurso urbanístico foi definida à maneira de um sistema; manifestava a capacidade de conceber e construir o espaço a partir de uma tripla projeção. A perspectiva de um passado resultante daquilo que a razão técnica pode fazer sobre a natureza e das rentabilizações financeiras sobre o espaço urbano. O diagnóstico dos males do presente, minuciosa descrição dos problemas de aeração, ventilação, congestionamento do tráfego e dos sistemas de coleta de lixo, abastecimento e distribuição de água. O prognóstico de um futuro incerto, baseado na hipótese ou na necessidade do seu saneamento, do seu embelezamento, da sua funcionalidade e da sua organização, em suma, baseado numa reforma.

O contato com os vestígios dos trabalhos de remodelação da cidade, mais tarde compendiados no relatório da Comissão Urbanística, autorizou a visão de conjunto da cidade, a percepção do panorama que ela possibilitava. Uma sociedade multíplice insinuou-se no interior da cidade planejada e visível: supunha-se que os habitantes da cidade correspondiam a manipulaçóes sobre os elementos fundamentais da ordem construída; supunha-se que fossem figuras ambulatórias definidas pelo sistema urbano; supunha-se, ainda, existir um nível normal e normativo ao qual se podiam referir as práticas do espaço catalogadas pela administração pública (Agache, 1930, p. 124). Assim, a concepção da cidade unificada pelo planejamento racional comportava um conjunto de signos de fusão, de cooperação, de energia, de ação, de conquista e redenção por meio da tecnologia. Identificando o gesto de eqüidade promovido por essa concepção de urbanismo, Nicolau Sevcenko (1998, p. 136) nota a homologia que, nesse período, existiu entre as reformas urbana e social: a maneira de intervir no espaço urbano deveria ser um elemento que dispusesse à ação, que apresentasse com nitidez a expressão da função e que permitisse a fundamentação de um novo paradigma para a sociedade, 
Os artifíces da metrópole: anotações sobre a transformação da vida urbana carioca...

cuja base seria a eqüidade, a prosperidade e a solidariedade. Dois postulados, ao que me parece, condicionam a validade dessa aproximação.

Primeiro, é possível verificar o interesse dos urbanistas e engenheiros em dispor de um nível normal ou normativo ao qual se pudessem referir os desvios e as variações da apropriação dos espaços da cidade. Em torno desse desejo pareceram girar esses dois pólos da reforma, que foram o urbano e o social. Depois, analisando os artigos publicados na Revista Brasileira de Engenharia que se ocuparam da remodelação da cidade, fica rapidamente perceptível a obsessão desses profissionais com as fundaçôes, com os formatos e com as exigências da remodelação. Nessa perspectiva, pode-se descobrir uma analogia com o modernismo vigente no Rio de Janeiro, o qual, preocupado em dar uma forma de expressão para a nacionalidade, coincidia com o investimento da Comissão Urbanística na organização de uma experiência social para o plano de obras das remodelaçôes da cidade do Rio de Janeiro. De fato, a cidade foi vista como um espaço de unidade, comunidade e solidariedade, um símbolo de movimento e conquista em direção ao progresso e, sobretudo, um signo da ação, pelas implicaçóes de ser fruto do trabalho de operários, pelo significado de cooperação de vários profissionais, desde o operário até o engenheiro e o médico-sanitarista. Por conta disso, analisando os monumentos públicos distribuídos em diferentes capitais do mundo, Nicolau Sevcenko percebe as intervençóes feitas no espaço urbano como "um símbolo de coesão e também de fundação do absolutamente novo, que anunciava uma nova era, um novo homem, uma nova sociedade" (1998, p. 138).

$\mathrm{Na}$ direção deste "novo", os percursos foram vários. O zelo remodelador e planificador de que o projeto urbano de Alfred Agache experimentou o vigor foi, certamente, o mais pavimentado. Os procedimentos de controle e administração do espaço publico tão convenientemente evocados nos planos de remodelação de Pereira Passos, nas obras da Prefeitura do Rio de Janeiro de Carlos Sampaio e também no plano de remodelação de Agache informam sobre o agenciamento psicológico, físico e emocional que foi o processo de recriação da cidade do Rio de Janeiro. Esse agenciamento conduziu a uma convergência, cheia de conseqüências para as atividades do pla- 
nejamento público, entre o desenho dos espaços fundamentais para a convivência urbana e o traçado de leis e códigos minuciosos para governar a multiplicidade humana responsável pelo uso desses espaços.

\section{A presença escolar na reinvenção da urbanidade}

A relação escriturária da legislação com o espaço público que se desencadeou por meio dos processos de controle e administração concedeu um lugar destacado à organização educacional. A constituição de um sistema escolar tomou corpo com o avanço da urbanização, legitimado no sentimento nacional que era capaz de consolidar. No estudo em que analisa como foi organizada a escolarização na cidade do Rio de Janeiro, Clarice Nunes surpreende seus responsáveis redefinindo o campo educacional "num espaço urbano que estabeleceu com a modernidade uma relação peculiar a partir da condição de capital política, da ambição do cosmopolitismo e da convicção de que o discurso da cidade era um discurso metonímico para todo o país" (1996, p. 156). A escola serviu-lhe como um protocolo de leitura da cidade: por meio de operações disciplinares, cuja propriedade era transformar o imaginário e o trabalho coletivo estabelecendo classificações e distribuições hierárquicas, a escola articulou sua relação com a cidade.

O primeiro efeito da leitura é o entendimento da instituição escolar não apenas como tendência ordenadora e controladora, mas também dotada da capacidade de fabulação, capaz de criar obstáculos à ação dos seus planejadores, que pressiona as medidas impostas e até as reorienta (Nunes, 1996, p. 157). Em suas análises, Nunes procura captar a especificidade da escola dentro da cultura urbana. Propõe uma interpretação do modo como o processo de urbanização preencheu o espaço escolar com as vocações da própria cidade. Assim, a fragmentação social, a precariedade da vida urbana, o processo de ocupação dos morros e sua favelização estiveram em foco nas inquietações dos educadores com relação à realização das composições exigidas pela manutenção do poder instalado no governo da capital da república. Simultaneamente, percebem as resistências urbanas cotidianas às forças coercitivas produzidas pela cultura científica forjada nas faculdades de medicina e nos laboratórios, pela faculdade escriturária implicada nas funções da advocacia e da burocracia administra- 
Os artifíces da metrópole: anotações sobre a transformação da vida urbana carioca...

tiva ou, ainda, pelo registro gráfico das operações intelectuais sobre a cidade, produzido nas escolas de engenharia e arquitetura. Como resultado se obtém uma reflexão sobre a reorganização morfológica e cultural que o urbano gerou na escola primária republicana na cidade do Rio de Janeiro.

É possível estender essa problemática apontada por Clarice Nunes às relações que as formas de ensinar mantiveram com a vida urbana, e até mesmo transpô-la para as relações de apropriação dos programas ensinados. Isolada no campo das reformas da instrução pública, o urbano incide sobre a cultura escolar apenas como um ponto de referência de uma distinção muito geral entre os processos educativos e os procedimentos de organização e resistência do espaço urbano, pois os problemas urbanos situavam na escola duas espécies de movimentos aparentemente contrários, um de exterioridade, o outro, interior. Exteriormente, a cidade sintetizava a crise gerada pelas dificuldades de intervenção das autoridades municipais sobre sua desordem, sendo apropriada pela escola nos seus códigos de realização e funcionamento, como o demonstram Nunes (1994, p. 196), ao advertir que uma escola não é apenas o produto das suas técnicas, e, em estudo mais antigo, Carlos Monarcha (1989), quando a escola busca na realização técnica da pedagogia o produto de um modelo de modernidade encarnado pela cidade. A interiorização da metrópole pela escola deu-se, no entanto, por meio de prescriçóes acerca dos princípios que governavam a seleção do conhecimento transmitido, das estratégias pedagógicas, dos compêndios científicos, dos recursos disciplinares e dos modelos de avaliação do desempenho escolar.

Considerada sob este último prisma, a escola pública serviu à cidade mediante programas, regulamentos, proclamaçóes, procedimentos e mediante um ensino destinado a sustentar e justificar a cultura urbana. É um ponto de vista que, depois de ter aproximado dos processos educativos os procedimentos de organização do espaço urbano, permite interpretá-los no plano da enunciação performativa, ou ao menos compreender nessa outra perspectiva aquilo que num processo educativo é indissociável do espaço habitado. A realidade material da escola, na qual está implicada não só o edifício ou os materiais de ensino, mas, também, o ambiente doméstico de onde provém o aluno e, sobretudo, o percurso utilizado para se chegar às aulas, é parte do repertório de práticas educacionais que opõem as estratégias de 
ocultamento e aprisionamento a modelos de visibilidade, abertura e transparência de idéias, pessoas e espaços. A disputa faz-se por meio das caligrafias que bradam sem gritar nas salas de aula (Vidal, 2000a), dos ruídos abafados pela leitura silenciosa (Vidal, 1998; 2000b), dos gestos feitos de violências executadas fora da escola (Carvalho, 1997) e, talvez, pela própria história de vida de cada um (Veiga \& Faria Filho, 1999). Nesses anos, os resultados dessas disputas configuraram uma primeira tentativa de levar para a prática os projetos mais ou menos utópicos de reforma social ou de criação de uma nova sociedade.

Um indício da relação que as práticas educativas mantiveram com a reforma social foi precisamente fornecido pelo programa das escolas primárias adotado no ano letivo de 1929 por ocasião da reforma da instrução pública estabelecida pelo Decreto no 2.940 , de 22 de novembro de 1928. Por meio dele a cidade do Rio de Janeiro constituiu um centro de interesse importante na composição do plano esquemático para o ensino de conjunto. A cidade esteve situada como o núcleo de compreensão dos sentidos de expressões como patriotismo e cidadania bem como da formação do comportamento social, dos hábitos de higiene e de trabalho. Ela esteve circunscrita em uma instituição cada vez mais demarcada, regulada e condicionada pela própria capacidade de apropriação topográfica do espaço urbano vivido pelos seus praticantes, docentes ou discentes. Nessa perspectiva, mesmo que o programa das escolas primárias tenha respondido a modelos estáveis de ensino e aprendizagem, cujas estruturas e conteúdos já foram bem estudados (Carvalho, 1998), o seu plano esquemático para o ensino de conjunto (Distrito Federal, 1929, p. 68-81) acrescentava três categorias que inicialmente distinguiam suas possibilidades de uso: a geografia, o trabalho, a comunidade.

De saída, a ordem espacial que organizava a cidade do Rio de Janeiro foi apresentada em função do seu meio ambiente, ou antes, como afirmou Fernando de Azevedo, do seu substractum objetivo. Destacava-se dos programas o jogo entre as características naturais e suas conseqüências para o cotidiano urbano: a rua nos dias de chuva, enchentes, a irrigação das ruas, a configuração do relevo, do litoral, da orla marítima, das ilhas, do charco e dos terrenos de aterro do Distrito Federal, as questôes de ventilação, o abastecimento de água, a água parada, o impaludismo, a febre amarela e a campanha sanitária de Osvaldo Cruz compunham os tópicos elementares de percepção 
Os artifíces da metrópole: anotações sobre a transformação da vida urbana carioca...

da cidade. Esse quadro de enunciação geográfica da cidade foi ainda constituído pelas práticas escolares como a organização de museu dos principais produtos minerais do Distrito Federal e as excursôes a praças e jardins públicos dos arredores da escola.

No interior dessa caracterização foram selecionadas atividades profissionais e econômicas de realização espacial do lugar ocupado pela cidade. Assim foi que o trabalho cotidiano e profissional do povo no campo, na cidade e na orla marítima, nos primeiro e segundo anos, e a economia das regiōes urbana, rural e marítima do Distrito Federal, no terceiro ano, apareceram no programa das escolas primárias como índices necessários da vida na cidade. O desenho, a modelagem, a imitação de gestos por meio de brincadeiras ou da ginástica, os recortes, as colagens e as canções eram prescriçôes para fixar as diferentes atividades implicadas no cultivo agrícola, na pesca, nos serviços e nos ofícios por meio dos quais a vida urbana do Distrito Federal se organizava. A confrontação entre as condições do conforto pelo trabalho assalariado e o modo de vida dos "selvagens" era outra estratégia de apresentação da cidade às crianças.

A função produtiva do trabalho e da economia no perímetro urbano da cidade assegurava um segundo repertório de caracteres apropriados ao esforço de legitimar e justificar os modi vivendi de uma metrópole: o repertório histórico da evolução urbana da cidade do Rio de Janeiro. O confronto entre passado e presente apontava para o progresso obtido pelas sucessivas administrações municipais. Os serviços públicos marcavam a diferença entre as estruturas antigas e modernas de distribuição de água, pão, leite e carne, dos processos de iluminação artificial e do embelezamento das fachadas de moradia. Desse modo, o programa tanto falava sobre a cidade como a fazia aparecer.

Ligando as circunstâncias naturais do Rio de Janeiro e o trabalho humano de transformação do seu meio ambiente, abrindo rumos e direções, o programa das escolas primárias tomou a organização social da ocupação, da administração e da transformação das condições de vida do espaço urbano como ponto de ensino e aprendizagem. Transcrevia a cidade por intermédio dos seus núcleos associativos, desde o núcleo familiar até a estrutura dos serviços públicos passando pela instituição escolar e pelos passeios públicos da cidade. Vinha 
destacada a caracterização da organização administrativa e da evolução histórica do Distrito Federal, a articulação institucional da escola para exercer influência na sociedade e, ainda, a descrição de uma ordem moral para uma convivência cosmopolita na cidade.

Assim, num primeiro plano, era afirmado o modo como o Distrito Federal era administrado, sua dependência do governo federal, os três poderes, a Prefeitura, o Conselho Municipal, os serviços municipais, a defesa sanitária, o governo Pereira Passos e a arrecadação dos impostos. O significado dessa estrutura encontrava no percurso histórico da cidade o seu sentido. Os episódios de disputa política ocorridos no período colonial vinham acrescidos dos principais episódios da intervenção urbana promovidos pelas administraçôes Pereira Passos, Paulo de Frontin e Carlos Sampaio numa aproximação que reforçava o paralelismo entre a função pública do poder político e a do urbanismo. Depois, num outro plano, a escola era apresentada não só como extensão do lar, mas, sobretudo, como local de organização cívica que, pela construção da autonomia dos alunos por meio do autogoverno, semelhante ao das instituições políticas da cidade, pela visita a locais evocativos do passado da cidade, pela projeção cinematográfica de aspectos da cidade antiga, insistia na formação de um patriotismo civil necessário à consolidação da Nação. Além de intermediária entre a vida doméstica e pública, foi responsabilidade da escola a construção de uma ordem moral composta pelo sentimento de solidariedade, pelo espírito de cooperação e pela consciência do dever de cada cidadão de interessar-se pelo bem público e pelo governo de sua terra. Neste outro plano, a educação escolar fez corresponder à arte de moldar percursos uma arte de moldar cidadãos.

Parece provável que esta experiência curricular atribuiu à cidade um valor cognitivo. A vivência numa metrópole foi vista pelo programa das escolas primárias, publicado na mesma ocasião da ação da Comissão Urbanística chefiada por Alfred Agache, crivada de exigências: higiene, trabalho, alfabetização, ordem, obediência, cooperação, solidariedade e responsabilidade. A sua leitura afirmava operaçōes anunciadoras que ultrapassavam tanto o traçado gráfico da metrópole quanto as modalidades cotidianas presentes no uso da cidade, isto é, os ritmos, as práticas e os valores urbanos. 
Os artifíces da metrópole: anotações sobre a transformação da vida urbana carioca...

Rio de Janeiro, anos de 1920: a reforma como perícia

A concretização dessa leitura requisitou um teatro de ações. A autorização que o programa das escolas primárias deu ao professorado não foi só de ordem jurídica, relativa a leis ou juízos. Em parte serviu também para dar legitimidade às ações efetivas. Sistematizou um campo semântico que autorizava práticas escolares polivalentes sobre o processo educativo. Quis disseminar práticas sociais para lhes abrir um campo de efetivação. Nesse esforço, a diferenciação dos lugares sociais, as operaçóes sobre os percursos da cidade, a vigilância dos gestos costumeiros de expressão ou sociabilidade, a recitação de caminhos e paisagens informavam a prática docente a partir do espaço escolar. Essas operações, o programa não as criara, articulara-as e manipulara-as. Na escola pública, porém, elas foram uma maneira de apreensão tátil da vida urbana.

A história dessa apropriação começava pela Diretoria-Geral de Instrução Pública, com decretos. Depois da organização seminal da instrução carioca feita por Medeiros e Albuquerque, a regulamentação e a implementação de reformas tão diferentes quanto as de 1911, Decreto no 838, de 1914, Decreto no 981 , e de 1928, Decreto no 3.281 , legitimaram sucessivos instrumentos para a administração pública produzir praticantes do discurso normativo. Os resultados dessa fixação foram problemáticos, como mostra Clarice Nunes, mas obtiveram credibilidade perante aquilo que havia sido proposto pelo repertório de ações envolvido na reconfiguração da cidade do Rio de Janeiro: a reforma social.

O encontro que se deu em fins da década de 1920 pareceu, entretanto, único. O governo da Prefeitura do Distrito Federal operou intervenções na configuração urbana da cidade do Rio de Janeiro ao mesmo tempo que possibilitou a reforma da sua instrução pública. Se considerado esse ponto de interseção no contexto de uma mesma plataforma administrativa, a urbanização planejada no interior da Comissão Urbanística da Prefeitura e a reforma da instrução pública implementada entre 1927 e 1930 pela Diretoria-Geral de Instrução Pública representaram, na verdade, o paradigma de uma nova cidade: não somente saneada, organizada e culta, mas, sobretudo, integrada. 
Esse entendimento amplificava a atenção do projeto de reforma da instrução perante a decifração da cidade. Percebia as tentativas de levar para a prática o tão bem conhecido repertório de açôes para promoção da reforma social como parte do programa de ensino das escolas primárias. E, de fato, relacionava planejamento urbano e reforma da instrução numa só chave de entendimento, a da perícia. Os discursos intelectuais cediam aos poucos, perdendo importância e espaço, tornando-se quase inoperantes na ordem técnica em que o perito e o burocrata, dentro em breve confundidos, consolidaram matrizes programáticas demarcadas não somente por um código legislativo, mas, sobretudo, por um campo profissional específico, por uma literatura especializada. $\mathrm{O}$ valor instrumental da profissionalização circunscrevia as criaçôes do saber aos cálculos de custos e efeitos adotados pelas instituiçóes firmemente empenhadas em substituir os mecanismos incontrolados e espontâneos da sociedade por um plano traçado com monitoria estatal. Nesses anos posteriores à Belle Époque, o credenciamento do saber profissional era necessariamente vazado pela sua capacidade de fazer proliferar instrumentos capazes de refazer o espaço habitado.

Recebido em setembro de 2003 e aprovado em dezembro de 2003.

Referências bibliográficas.

AGACHE, A. (Dir.). Cidade do Rio de Janeiro: extensão, remodelação, embellezamento; organizaçóes projectadas pela administração Antonio Prado Junior. Tradução Francisca de Souza. Paris: Foyer Brésilien, 1930.

BARRETO, C. Século da raça. Rio de Janeiro: Francisco Alves, 1923.

BARRETO, C. Um dos nossos mais sérios problemas. Correio da Manhã, Rio de Janeiro, 6 ago. 1924.

CARVALHO, M.M.C. Quando a história da educação é a história da disciplina e da higienização das pessoas. In: Freire, M.C.F. (Org.). História social da infância no Brasil. São Paulo: Cortez, 1997. p. 269-286. 
Os artifíces da metrópole: anotações sobre a transformação da vida urbana carioca...

CARVALHO, M.M.C. Por uma história cultural dos saberes pedagógicos. In: Souza, C.P.; Catani, D.B. Práticas educativas, culturas escolares, profissão docente. São Paulo: Escrituras, 1998.

CASTRO, P.J. O urbanismo. Jornal do Brasil, Rio de Janeiro, 10 dez. 1926.

CERTEAU, M. A invenção do cotidiano: artes de fazer. Petrópolis: Vozes, 1994.

CHALHOUB, S. Cidade febril: cortiços e epidemias na corte imperial. São Paulo: Companhia das Letras, 1996.

A DEFESA da sociedade contra os tóxicos. Gazeta dos Tribunaes, Rio de Janeiro, 9 ago. 1927.

DISTRITO FEDERAL (Brasil). Programmas para os jardins de infancia e para as escolas primarias. Rio de Janeiro: Officinas Graphicas do Jornal do Brasil, 1929.

FONSECA, A. Minhas razões. Gazeta dos Tribunaes, Rio de Janeiro, 22 jul. 1927.

FONTENELLE, O.P. Problemas policiaes. Rio de Janeiro: Tip. do Jornal do Commercio, 1927.

FRIDMAN, F. Os donos da terra carioca: alguns estudos de caso. In: Donos do Rio em nome do rei: uma história fundiária da cidade do Rio de Janeiro. Rio de Janeiro: Zahar; Garamond, 1999. p. 233-252.

FROTA PESSOA, J.G. Educação e rotina. Rio de Janeiro: Industrial Graphica, 1924.

GOMES, A.C. Essa gente do Rio... Rio de Janeiro: FGV, 1999.

MARQUES, J.C.A. Menores abandonados e delinqüentes. São Paulo: Saraiva, 1925.

MONARCHA, C. A reinvenção da cidade e da multidão: dimensões da modernidade brasileira: a escola nova. São Paulo: Cortez, 1989.

MORAES, A.E. Ensaios de patologia social: vagabundagem, alcoolismo, prostituição e lenocínio. Rio de Janeiro: Leite Ribeiro, 1921. 
NUNES, C. A escola reinventa a cidade. In: Herschmann, M.; PereiRA, C.A.M. A invenção do Brasil moderno: medicina, educação e engenharia nos anos 1920-30. Rio de Janeiro: Rocco, 1994. p. 180-201.

NUNES, C. Cultura escolar, modernidade pedagógica e política educacional no espaço urbano carioca. In: Herschmann, M.; Kropf, S.; Nunes, C. Os missionários do progresso: médicos, engenheiros e educadores no Rio de Janeiro; 1870-1937. Rio de Janeiro: Diadorim, 1996. p. $155-224$.

ORICO, O. O melhor meio de disseminar o ensino primário no Brasil. Rio de Janeiro: Edição do Autor, 1918.

PEIXOTO, A. Criminologia. Rio de Janeiro: Guanabara, 1932.

PRADO JÚNIOR, A. A reforma da instrucção publica no Districto Federal. Jornal do Brasil, Rio de Janeiro, p. 8, 5 out. 1927.

RAMA, A. A cidade das letras. São Paulo: Brasiliense, 1985.

A REMODELAÇÃO da capital federal. Revista Brasileira de Engenharia, Rio de Janeiro, v. 9, t. 18, n. 2, p. 57-62, ago. 1929.

SAMPAIO, C. Urbanismo. Revista Brasileira de Engenharia, Rio de Janeiro, v. 8, t. 14, n. 4, p. 131-132, out. 1927.

SANTOS NETO. Criminalidade e justiça. Rio de Janeiro: Cia de Livros e Papéis, 1926.

SCHIAVI, A. Infância e criminalidade. São Paulo: Irmãos Ferraz, 1926.

SEVCENKO, N. Literatura como missão: tensões sociais e criação cultural na Primeira República. São Paulo: Brasiliense, 1986.

SEVCENKO, N. Entre o paraíso e o inferno. Arte Pública, São Paulo, SESC, 1998. p. 136-143.

VEIGA, C.G.; FARIA FILHO, L.M. Infância no sótão. Belo Horizonte: Autêntica, 1999. (Coleção Historial, 4).

VIDAL, D.G. Práticas de leitura na escola brasileira dos anos 1920 e 1930. In: Faria Filho, L.M. (Org.). Modos de ler, formas de escre- 
Os artifíces da metrópole: anotações sobre a transformação da vida urbana carioca...

ver: estudos de história da leitura e da escrita no Brasil. Belo Horizonte: Autêntica, 1998. p. 87-116.

VIDAL, D.G. A escola nova e o processo educativo. In: Lopes, E.M.T. et al. (Org). 500 anos de educação no Brasil. Belo Horizonte: Autêntica, 2000a. p. 497-518.

VIDAL, D.G. Livros por toda parte: o ensino ativo e a racionalização da leitura nos anos 1920 e 1930 no Brasil. In: Abreu, M. (Org.). Leitura, história e história da leitura. Campinas: ALB; Mercado das Letras; São Paulo: FAPESP, 2000b. p. 335-355. 